\title{
System-Level Performance Evaluation of ATD-1 Ground-Based Technologies
}

\author{
Todd J. Callantine, ${ }^{1}$ Michael Kupfer, ${ }^{2}$ Lynne Martin, ${ }^{3}$ Joey Mercer ${ }^{4}$ \\ San Jose State University/NASA Ames Research Center, Moffett Field, CA, 94035 \\ and \\ Thomas Prevot ${ }^{5}$ \\ NASA Ames Research Center, Moffett Field, CA, 94035
}

\begin{abstract}
A series of large-scale human-in-the-loop simulations were conducted in the Airspace Operations Laboratory (AOL) at NASA Ames Research Center to evaluate the system-level performance of NASA Air Traffic Management Technology Demonstration-1 (ATD-1) ground-based technologies. The ATD-1 ground-based technologies are the Traffic Management Advisor for Terminal Metering (TMA-TM) and Controller-Managed Spacing (CMS) tools. The simulations compared current operations to ATD-1 operations for peakperiod arrivals to Phoenix Sky Harbor International Airport (PHX). Results indicate that controllers new to ATD-1 operations can increase the use of Performance-Based Navigation (PBN) in complex arrival flows without undue increases in workload.
\end{abstract}

\section{Introduction}

A REA Navigation (RNAV) is an important aspect of Performance-Based Navigation (PBN). Consistently enabling fuel-efficient descents on RNAV arrivals is a key step toward broader use of PBN operations. Today, however, efficient RNAV descents are difficult to manage with high throughput due to aircraft performance differences and flight-trajectory uncertainties. Excessive miles-in-trail restrictions prior to descent limit throughput, and 'step-down' control techniques for ensuring safe separation interrupt efficient descent profiles. Furthermore, without a global plan for managing arrivals, terminal-area controllers must rely on vectoring for sequencing, which also interrupts RNAV operations. Scheduling arrival, and providing tools to aid controllers in managing aircraft to the schedule and merging RNAV arrival flows without vectoring is a promising approach for realizing efficient PBN operations in the arrival domain.

The NASA Air Traffic Management Technology Demonstration-1 (ATD-1) is a multi-year collaborative effort between researchers at NASA Ames and Langley Research Centers, the FAA, and industry partners to integrate, mature, and operationally demonstrate NASA-developed technologies for managing efficient arrivals with sustained high throughput. ATD-1 seeks to demonstrate increased, more consistent use of PBN arrivals, demonstrate an Automatic Dependent Surveillance-Broadcast (ADS-B) -In spacing application, and accelerate the transfer of NASA scheduling and spacing technologies for operational deployment. ${ }^{1}$ ATD-1 ground based technologies developed at NASA Ames provide arrival scheduling and controller aids for managing aircraft on efficient RNAV descents using primarily speed control; NASA Langley has contributed ADS-B-In-enabled Flight-Deck Interval Management (FIM) avionics and procedures to the ATD- 1 effort. $^{2-4}$

Following multiple integration and development simulations in laboratories at Ames and Langley, ${ }^{5,6}$ a series of large-scale human-in-the-loop simulations were conducted in the Airspace Operations Laboratory (AOL) at NASA

\footnotetext{
${ }^{1}$ Senior Research Engineer, Human Systems Integration Division, NASA Ames Mail Stop 262-4, AIAA Senior Member.

${ }^{2}$ Senior Research Engineer, Human Systems Integration Division, NASA Ames Mail Stop 262-4, AIAA Member.

${ }^{3}$ Senior Research Psychologist, Human Systems Integration Division, NASA Ames Mail Stop 262-4.

${ }^{4}$ Senior Research Psychologist, Human Systems Integration Division, NASA Ames Mail Stop 262-4, AIAA Member.

${ }^{5}$ Research Engineer, Human Systems Integration Division, NASA Ames Mail Stop 262-4, AIAA Senior Member.
} 
Ames to evaluate the system-level performance of the ATD-1 technologies. The simulations examined mixedRNAV-equipage peak-period arrival flows to Phoenix Sky Harbor International Airport (PHX) in both east- and west-flow landing configurations. The series of simulations began with a baseline simulation ('CA-5.1') conducted in July 2013, in which former Albuquerque ARTCC (ZAB) and PHX TRACON (P50) controllers and traffic managers performed current-day operations. CA-5.2 was conducted in September 2013 using the ATD-1 groundbased technologies to manage the same traffic. Most recently, in April 2014, CA-5.3 was conducted using the full suite of ATD-1 technologies. CA-5.3 included simulation trials with and without FIM operations. This paper does not consider FIM-related aspects of the 5.3 simulation in detail, because the results are still being analyzed. Instead, it focuses on the ATD-1 ground-based technologies and, in particular, system-level results with implications for how ATD-1 operations with scheduling and controller tools can improve the efficiency of arrival operations during periods of sustained high throughput.

Section II of the paper briefly presents background information. Section III describes the 5.1., 5.2, and 5.3 simulations, and notes changes to the ATD-1 ground-based technologies that were phased in for 5.3. Section IV presents results obtained thus far, beginning with some general observations. Section V presents conclusions.

\section{Background}

The ATD-1 ground-based technologies are the Traffic Management Advisor for Terminal Metering (TMA-TM) and Controller-Managed Spacing (CMS) tools. The TMA-TM uses information about RNAV arrival routes to landing runways to predict trajectories, and uses the predictions to allocate landing slots and generate conflict-free schedules along merging routes through the TRACON to the assigned runways while aircraft are still at cruise altitude. $^{7-10}$ Integration work performed under ATD-1 also enables the TMA-TM to compute the information required to display the CMS tools and distribute it to terminal-area controller workstations using the same communication interfaces as those used in the field. The CMS tools are slot markers, timelines, early/late indicators, and speed advisories (see Fig. 8). ${ }^{5,611,12}$ The timelines reflect the TMA-TM schedules directly, and the early/late indicators are derived directly from schedule; the slot markers and speed advisories are computed by the TMA-TM from the trajectories it generates for scheduling. Controllers use the tools to manage aircraft along efficient RNAV descents according to schedule, primarily by issuing speed instructions. ATD-1 operations using the TMA-TM contrast with current-day metering operations, as the fielded TMA currently only generates meter-fix schedules for achieving a desired acceptance rate for aircraft entering the TRACON, after which controllers sequence aircraft for landing and ensure separation primarily using vectors and inefficient step-down descents.

ATD-1 operations begin when the TMA-TM acquires each aircraft while it is still in cruise. TMA-TM assigns aircraft to runways and computes estimated times-of-arrival (ETAs) at the meter fix, runway, and at intervening terminal-area fixes where RNAV routes merge. It then uses the ETAs together with required spacing information to assign scheduled times-of-arrival (STAs) at each scheduling point. When an aircraft reaches a 'freeze horizon' specified at a site-specific distance (e.g., $200 \mathrm{nmi}$ ) from the TRACON boundary, the TMA-TM locks in its STA to provide a stable control target. Center controllers then begin working to 'precondition' the aircraft using speed instructions or path-stretching techniques as necessary to absorb delay. After preconditioning, center controllers reestablish aircraft on lateral RNAV routes and clear them to 'descend via' RNAV arrivals. These procedures enable flight crews to use their onboard Flight Management Systems (FMSs) to fly efficient profiles from cruise until landing, or until a radar vector is required to turn the aircraft to join the approach procedure. TRACON controllers use the CMS tools to issue speeds to ensure proper inter-arrival spacing while maintaining efficient RNAV descent profiles. Under nominal conditions, aircraft should cross the meter fix within their speed control margin for correcting residual schedule errors and adjusting for disturbances due to winds or other factors inside the TRACON. Controllers issue FIM clearances to equipped aircraft once the aircraft has been preconditioned and issued a 'descend via' clearance. Controllers retain separation responsibility, and may interrupt RNAV arrivals and/or suspend FIM operations if they deem small adjustments from the nominal speed profile insufficient to maintain safe separation. Procedures and clearance phraseology for these operations are documented in the ATD-1 Concept of Operations. ${ }^{13,14}$

\section{Simulation Studies}

The 5.1, 5.2, and 5.3 simulations were intended to facilitate system-level comparisons of operations under the most realistic conditions possible. The simulations use routings, airspace sectorization, and controller positions consistent with real-world operations. Controllers experienced in ZAB and P50 operations used high-fidelity Multi Aircraft Control System (MACS) controller-workstation emulations. All communications were via voice. Traffic scenarios were developed to accurately reflect actual PHX traffic samples drawn from peak-arrival periods in 2011, 
along with historical 2011 winds. While changes to the basic simulation configuration were kept to a minimum between the 5.1, 5.2, and 5.3 simulations, some changes proved necessary and reasonable given objectives and progress on other fronts. This section describes the elements of the simulations in detail.

\section{A. Routes and Airspace}

RNAV arrivals were implemented at PHX beginning in 2006. ${ }^{15}$ Fig. 1 provides an overview of the P50 TRACON location within ZAB, neighboring ARTCCs, the RNAV arrivals to each meter fix, and the names of the accompanying non-RNAV standard arrivals used in the simulations. Fig. 2 shows the high- and low-altitude center arrival sectors that were simulated to enable realistic metering operations; in some cases, simulated sectors represent allowable ZAB sector combinations.

In the 5.1 simulation, a TMA was configured like the currently fielded TMA using the fielded adaptation, and only the P50 and ZAB Traffic Management Coordinators (TMCs) used schedules. For ATD-1 operations in the 5.2 and 5.3 simulations, the TMA-TM generates schedules at the meter fixes, runways, and intervening TRACON merge points. Thus, the adaptation represents all routings along which aircraft can be scheduled and slot markers displayed. Figures 3 and 4 show the east- and westflow RNAV-equipped jet adaptations and the airspace assigned to each of the four controller positions inside the TRACON airspace. Arrivals landed on the PHX outboard

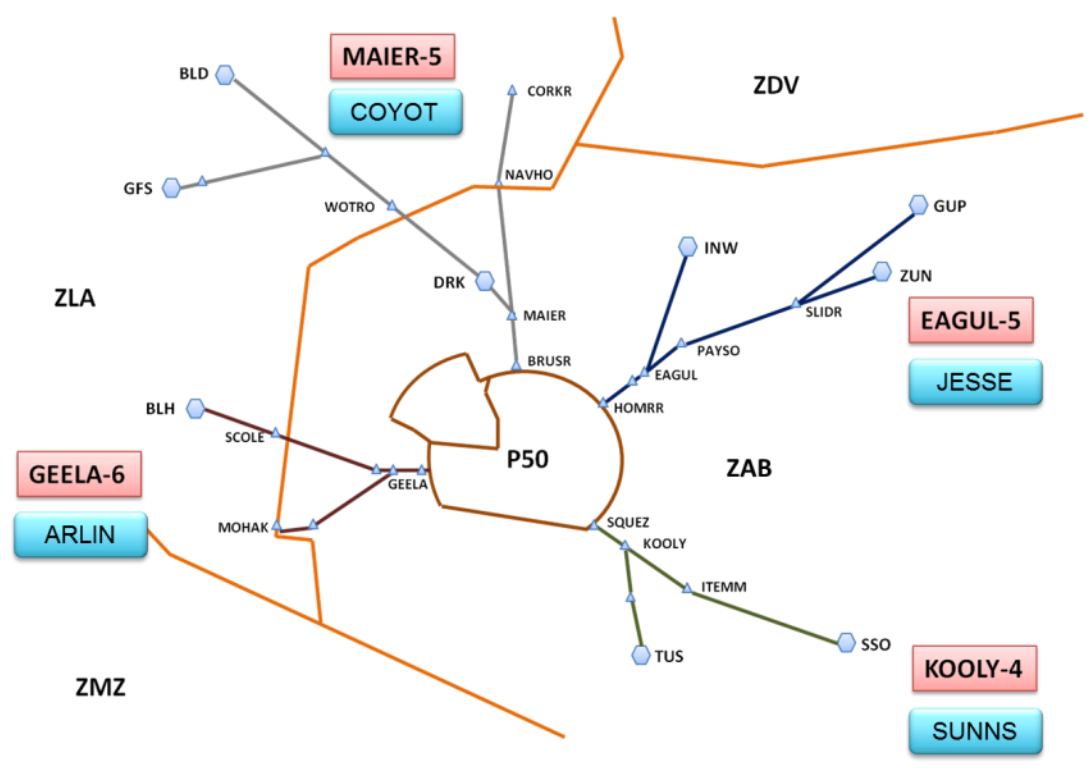

Figure 1. Route and airspace overview.

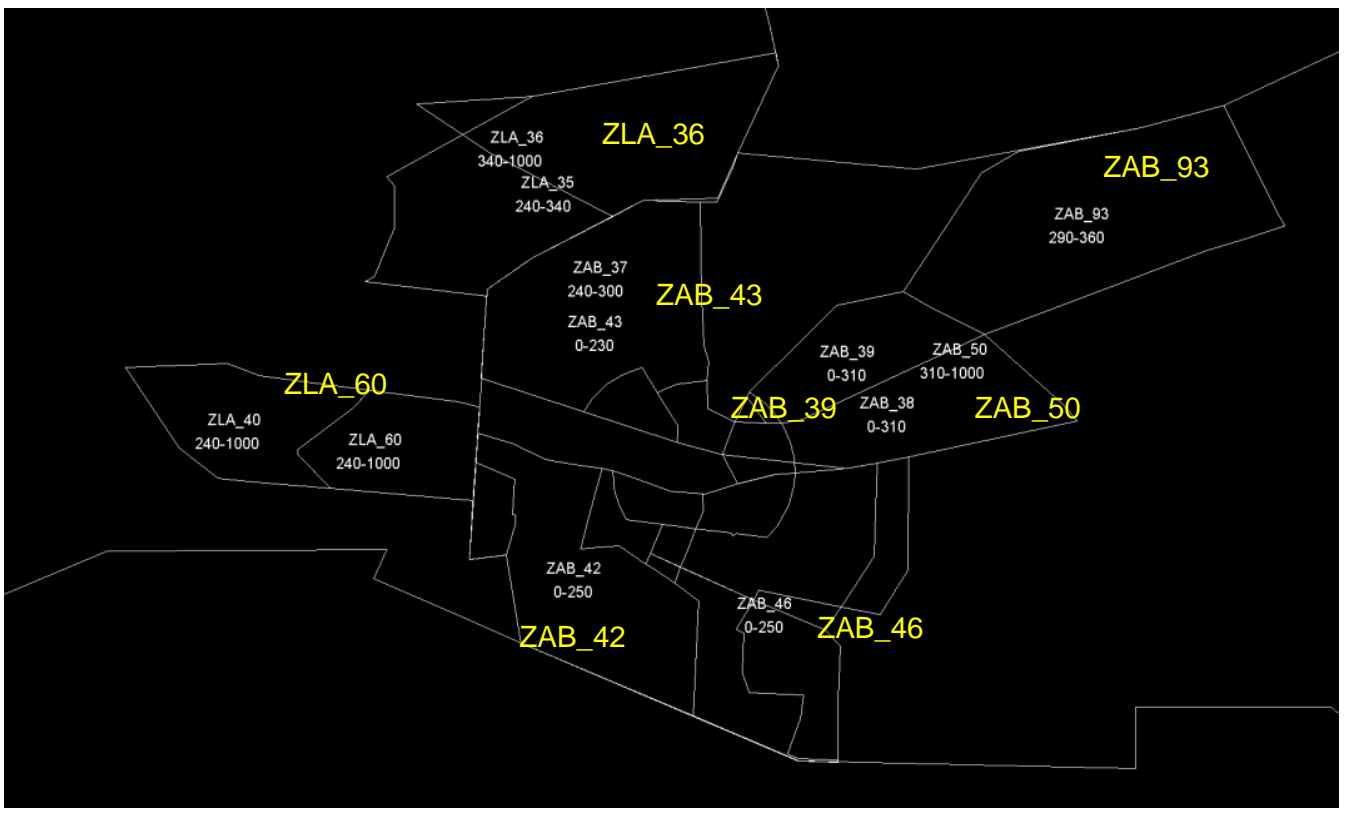

Figure 2. High- and low-altitude arrival sectors. 




Figure 3. East-flow adapted routes for RNAV-equipped jets.

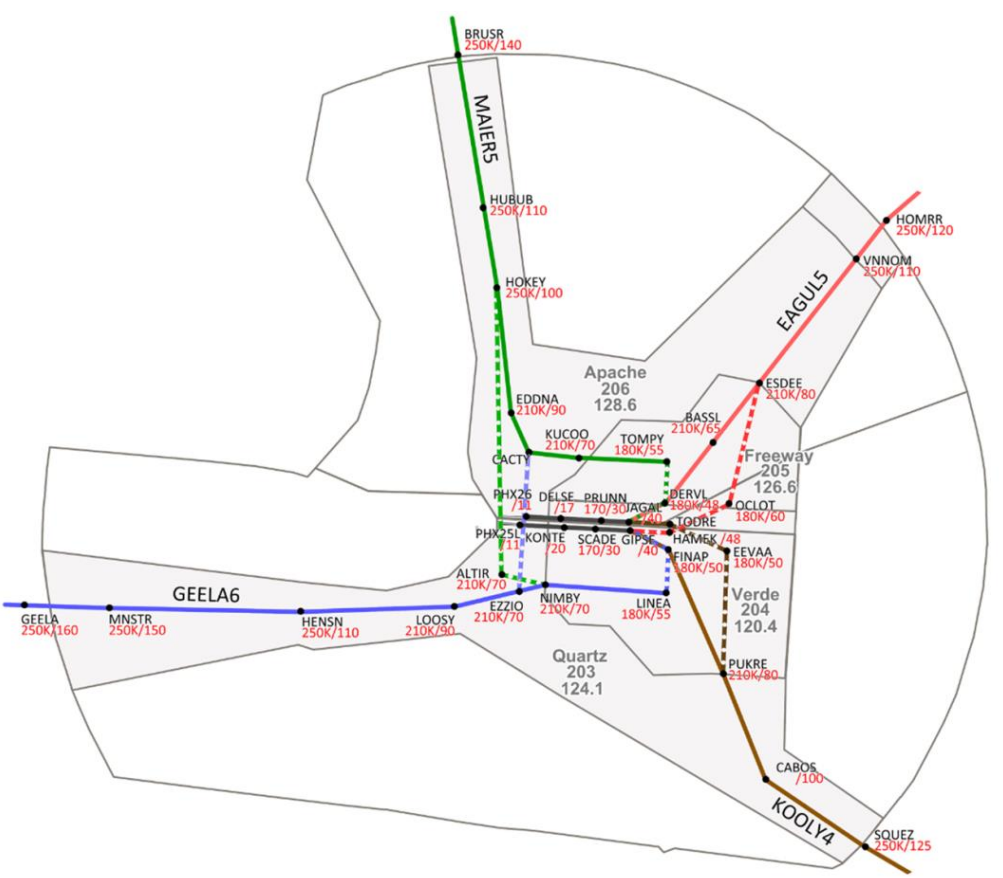

Figure 4. West-flow adapted routes for RNAV-equipped jets.

runways (08 and $07 \mathrm{R}$ in east-flow configuration; 26 and $25 \mathrm{~L}$ in west flow).

The route segments depicted with dashed lines in Fig. 3 and Fig. 4 indicate vectoring segments. They illustrate, first, how only 'short-side' arrivals connect to approach routings; controllers issue base-turn vectors to aircraft on downwind segments. Second, aircraft can be scheduled as 'crossovers' to the other landing runway. Crossovers must be vectored to the other side of the airport to join the corresponding approach; the adaptation specifies the routings used to schedule the crossover aircraft and display slot markers for them. The non-RNAV standard arrival routes identified in Fig. 1 were also represented using vectoring segments. For CA-5.2, the TMA-TM adaptation did not 
include routes for piston-engine aircraft and turboprops on some routings, so these arrivals were not included in TMA-TM schedules. For the 5.3 simulation, vectoring paths for these aircraft were added to west-flow route adaptation (shown in black in Fig. 5), enabling the TMA-TM to schedule and generate slot markers for them. Based on analyses of recorded $\mathrm{PHX}$ traffic, these routes only go to the shorter $25 \mathrm{~L}$ runway.

\section{B. Controller Displays}

ARTCC controllers used MACS emulations of the En-Route Automation Modernization (ERAM) workstations (Fig. 6). All functionality identified as important for realism was included in the emulations. A speed-assignment fly-out menu is shown in the upper left inset in Fig. 6. In the 5.2 and 5.3 simulations ERAM meter lists and Delay Countdown Timers (DCTs) near each aircraft target symbol were displayed with a precision of $10 \mathrm{~s}$ (rounded) (see insets, Fig. 6).

Terminal-area controllers used MACS

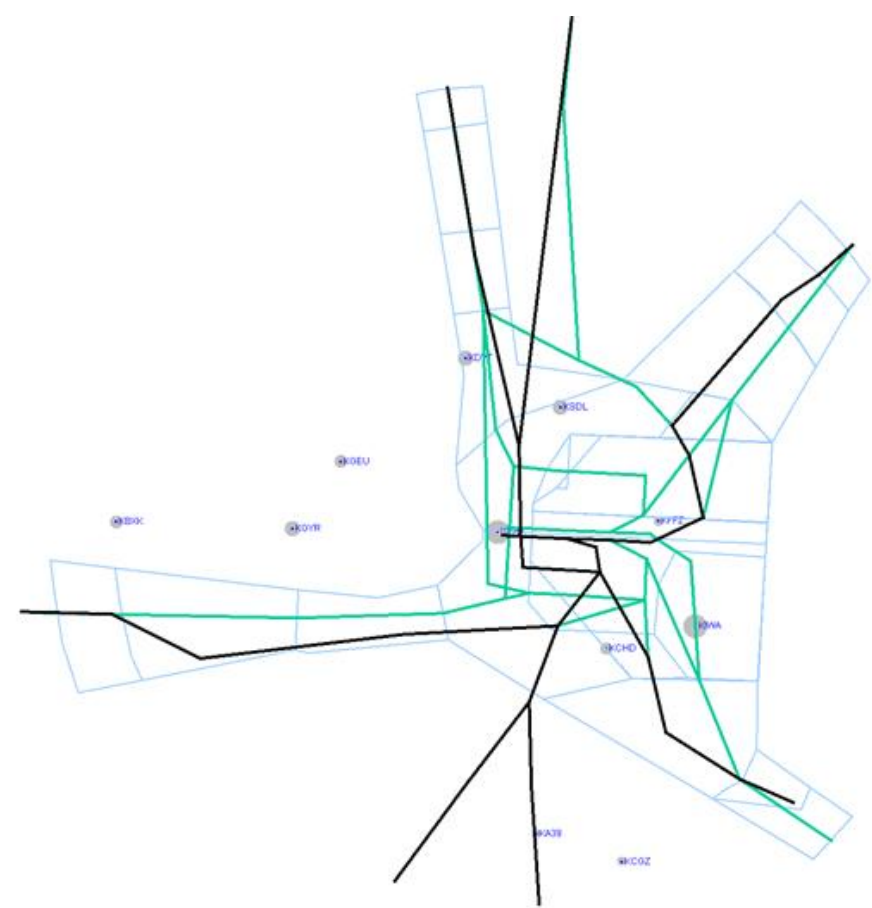

Figure 5. Adapted routes for pistons and turboprops in 5.3.

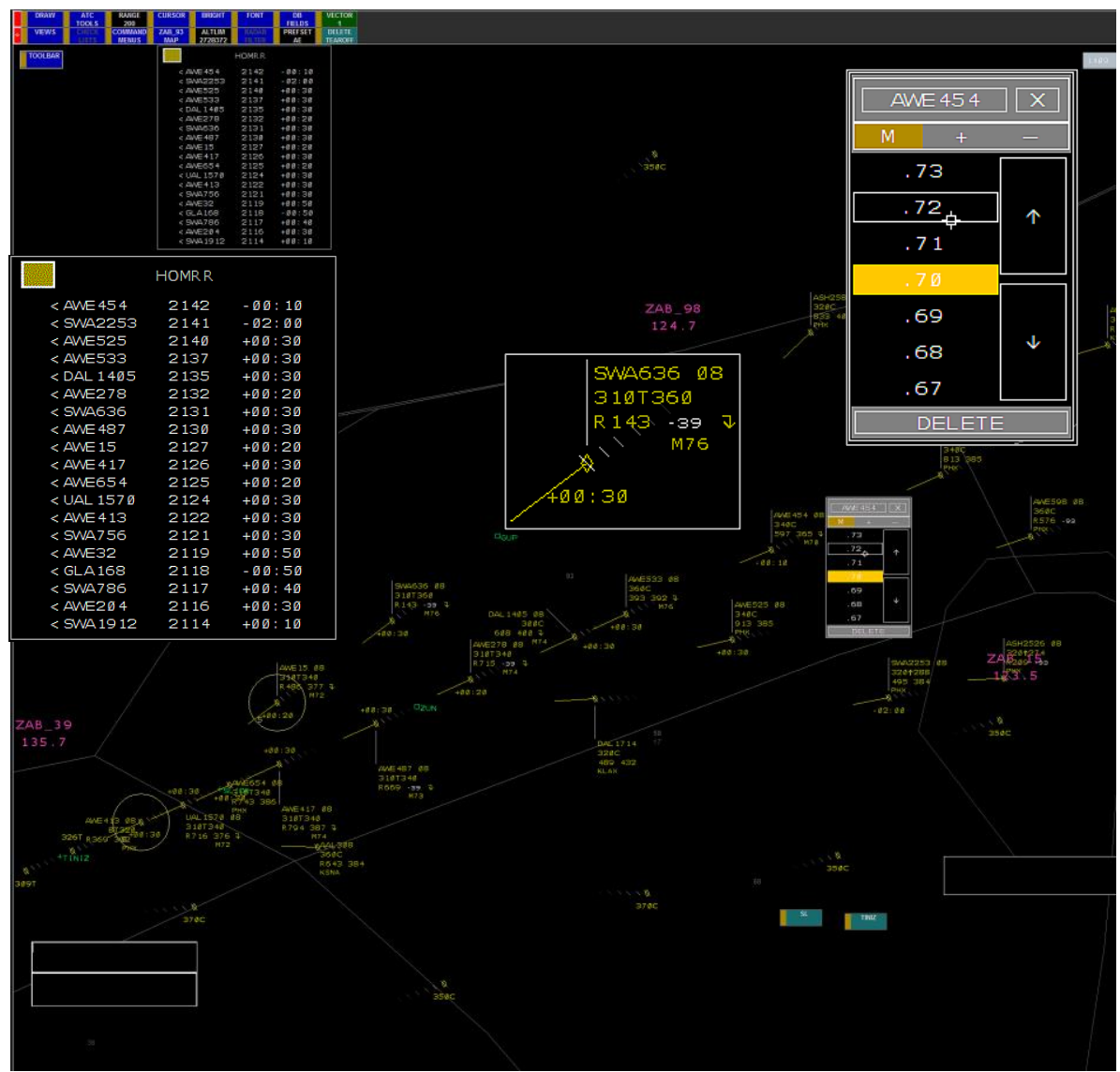

Figure 6. MACS ERAM workstation, with meter list, data block, and speed fly-out menu insets.

American Institute of Aeronautics and Astronautics 


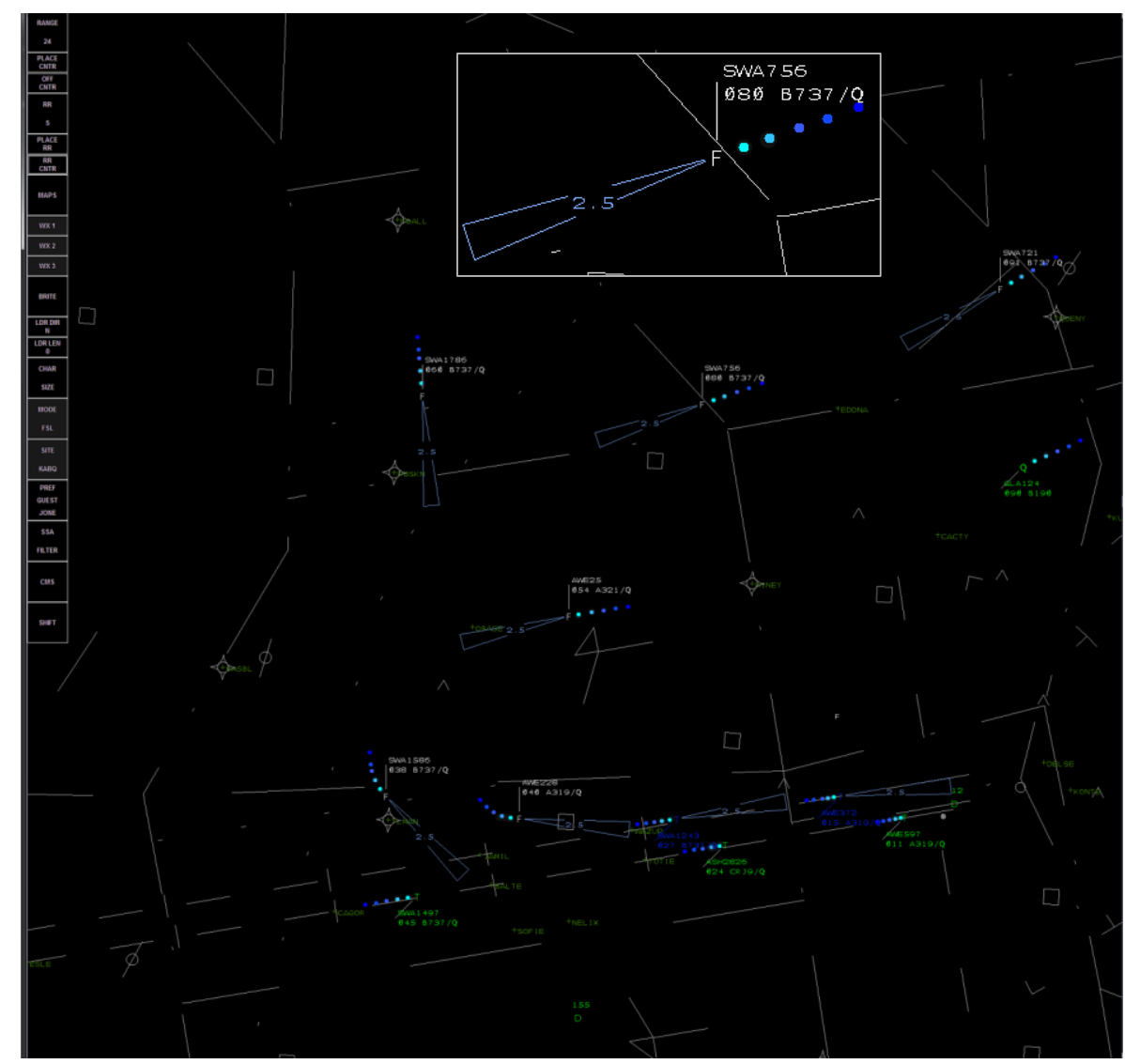

Figure 7. MACS STARS workstation, with inset showing current PHX data block.

emulations of Standard Terminal Automation Replacement System (STARS) workstations in the terminal area. Fig. 7 shows a basic STARS workstation (with 'spacing cones' displayed for gauging inter-arrival spacing) as used in the 5.1 simulation. The P50 configuration was used, with scratchpad information time-shared with altitude and aircrafttype information time-shared with groundspeed. CMS early/late indications and speed advisory information was added to the third line for the 5.2 simulation. Fig. 8 shows a STARS workstation configured with CMS tools for the 5.3 simulation. The 5.3 data-block configuration was modified from the 5.2 format to include candidate elements based on FAA Terminal Sequencing and Spacing (TSS) work; the third line includes a 'sequence numberlassigned runway' element followed by either the early/late indication (left inset, Fig. 8) or speed advisory (right inset, Fig. 8), if one is available. The timeline is located at the lower right in Fig. 8.

In addition, an airspeed bias was removed from the TMA-TM between 5.2 and 5.3, improving the accuracy of the TMA-TM airspeed calculations. The TMA-TM-estimated airspeed was therefore reintroduced near the target symbol, as in pre-ATD-1 CMS research. ${ }^{16}$ This enables TRACON controllers to compare the estimated airspeed of an aircraft to its computed slot-marker airspeed displayed near the slot marker (see Fig. 8), as a means of assessing when and how to adjust the aircraft's speed to keep it on schedule.

Traffic Situation Displays (TSDs) (see Fig. 10) and TMA-TM timeline displays were projected on control-room walls. Figure 9 shows the projected timeline displays during the 5.2 simulation. TMCs could configure their TMATM timeline displays as desired (see Fig. 11); the P50 TMC/Arrival Runway Coordinator (ARC) can be seen examining his timeline display in Fig. 9.

\section{Traffic Scenarios and Winds}

Traffic scenarios were developed based on actual PHX traffic samples drawn from peak arrival periods in 2011. One east-flow and one west-flow traffic sample were selected during which significant arrival rushes occurred along the EAGUL, MAIER, and GEELA flows. Developers carefully maintained initialization times and positions and assigned aircraft to the appropriate arrival routes. Departures and over-flights were adjusted to ensure any impacts to 


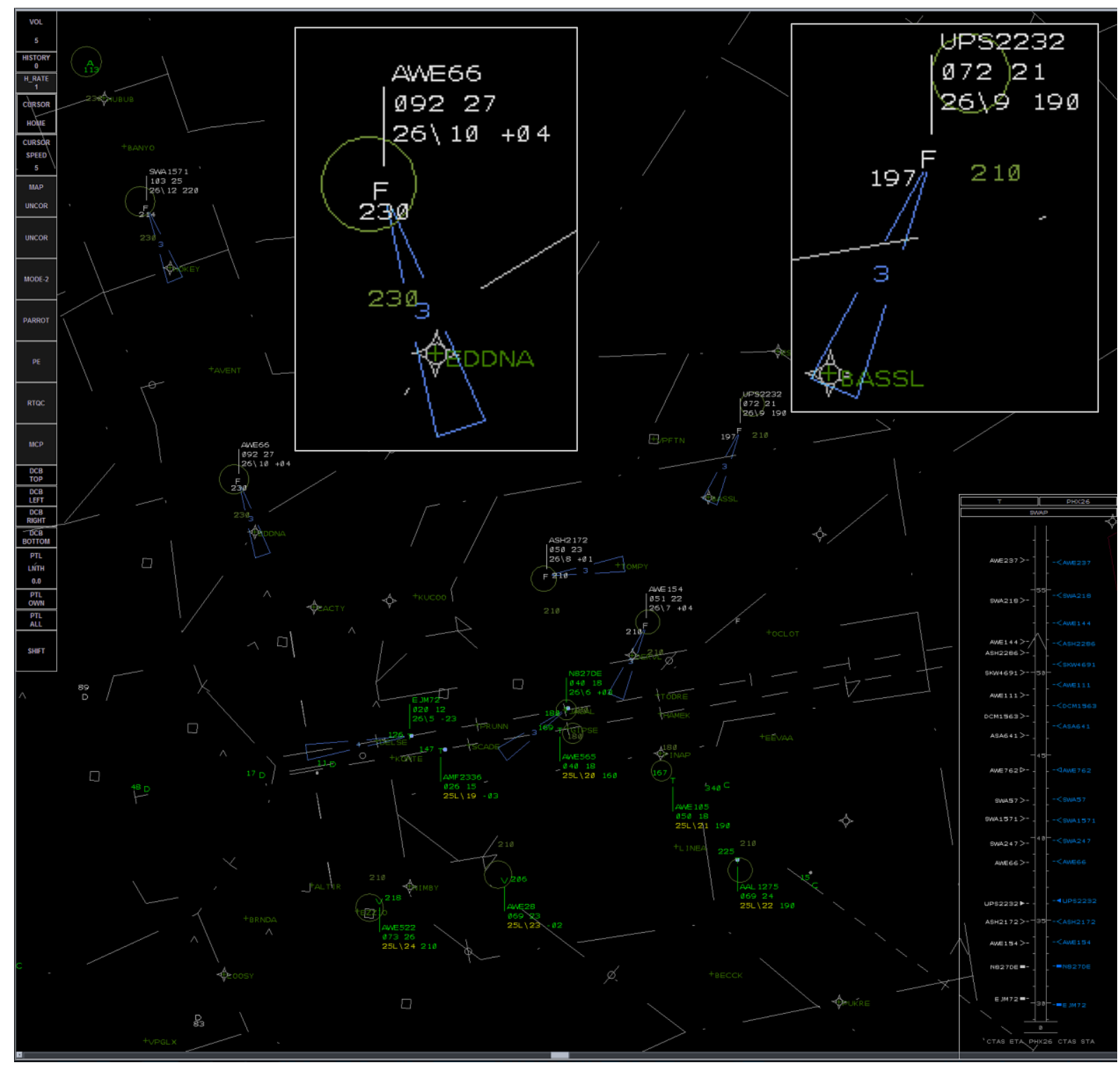

Figure 8. MACS STARS workstation with CMS tools.

the test sectors were delayed until the traffic flows were well established following initialization. Scenarios were designed with one-hour duration.

Environmental winds were also drawn from four historical samples chosen based on an extensive analysis; each traffic scenario was paired with four different sets of gridded winds that represent the most prevalent PHX wind patterns, as well as winds of different strengths, and crosswinds on final approach. The environmental winds were then paired with forecast winds for use in the ground-system computations, ensuring wind-forecast errors of approximately 10 kts RMS. Aircraft were also identified for replacement with single-pilot 'ASTOR' desktop simulators developed at NASA Langley, which participated as FIM-equipped aircraft in two-thirds of the 5.3 simulation trials. Special emphasis was placed on potential FIM-pairings for the 5.3 simulation, so the ASTOR assignments in 5.3 varied slightly from the prior simulations.

Although the east- and west-flow scenarios both captured arrival rushes along the EAGUL, MAIER, and GEELA arrivals, they represented morning and evening rushes into PXH, respectively, which have fundamentally different traffic characteristics. Figure 10(a) shows a snapshot of a TSD for an east-flow scenario upon initialization; Fig. 10(b) shows the east-flow traffic mid-way through the scenario. The traffic is comprised principally of RNAVequipped jets arriving PHX (red). Figures 10(c) and 10(d), on the other hand, show corresponding views of a westflow scenario, with its greater proportion of turboprops (cyan) and pistons (purple) arriving PHX, along with 



Figure 9. AOL air traffic control rooms.

satellite arrivals (green, white, yellow, and grey). The EAGUL flow predominates in the east-flow scenario, resulting in sustained high traffic in the ZAB_39 and ZAB_93 sectors, while the ZAB_42 and ZAB_43 sectorsalong with P50 - generally stay busier in the west-flow scenario.

The TMA-TM generates STAs for aircraft that meet specified separation requirements at meter fixes and runways. All the simulations used a $2.5 \mathrm{nmi}$ (Large-behind-Large), $4 \mathrm{nmi}$ (Large-behind-B757), and $5 \mathrm{nmi}$ (Smallbehind-Large) wake-vortex spacing matrix as input to the TMA-TM, with a $0.3 \mathrm{nmi}$ buffer added during the scheduling process. Minimum spacing of $2.5 \mathrm{nmi}$ was approved for operations on final approach within $10 \mathrm{nmi}$ of the landing runway. Given these criteria and the traffic demand, schedules usually contained some gaps.

Referencing the P50 TMC/ARC's custom timeline configuration for examples from the 5.3 simulation-in which STAs for north-side arrivals (to either runway 08 or 26) appear on the left, and STAs for south-side arrivals appear on the right of each timeline (ETAs were displayed on another timeline)-some schedule differences between the east-flow traffic (Fig. 11(a)) and the west-flow traffic (Fig. 11(b)) are evident (blue denotes frozen STAs). In addition to some large delay values for short-haul departures arriving PHX, more west-flow aircraft are scheduled to arrive on the south runway (per the adaptation changes shown in Fig. 5). An additional difference between the 5.2 and 5.3 scenarios was due to the use of TMA-TM runway-allocation functionality in 5.3. While the schedule allocated aircraft to runways more evenly in 5.3, it also resulted in more crossovers (see Table 1).

Sixteen traffic scenarios were initially created: four east-flow and four west-flow scenarios drawn directly from the recorded traffic (with aircraft call-signs randomized-denoted E1 through E4 and W1 through W4), and a

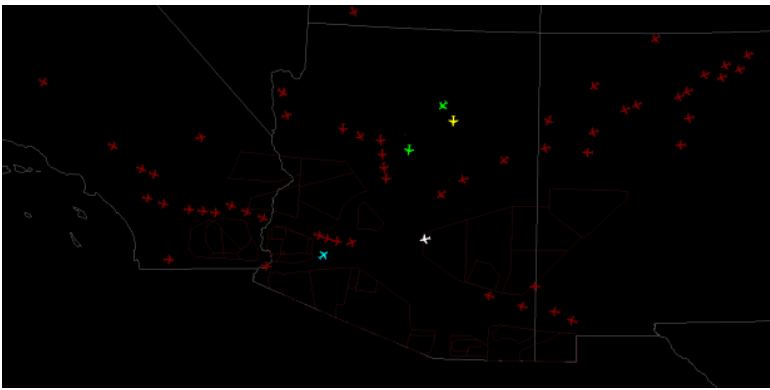

(a)



(c)

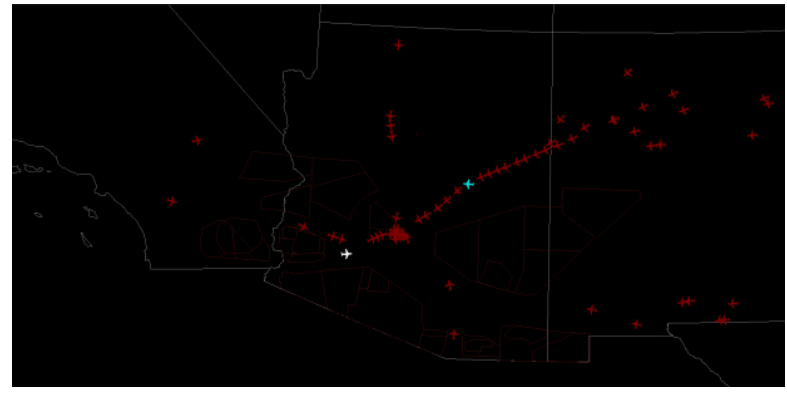

(b)

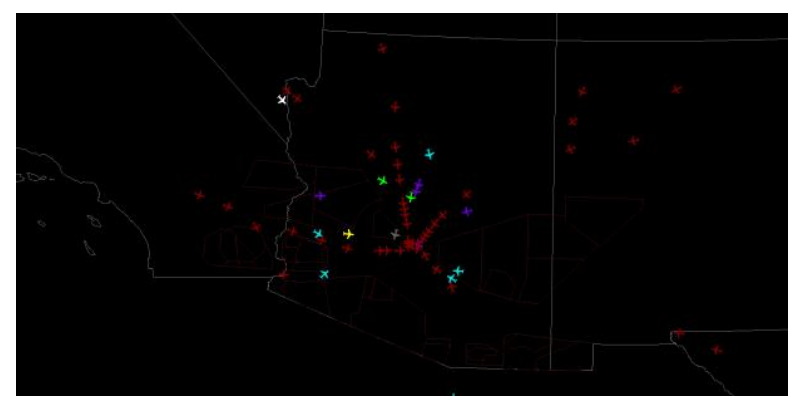

(d)

Figure 10. Traffic Situation Displays (TSDs) showing east- (top) and west-flow (bottom) scenarios. 
second set of eight in which six aircraft were added to the original east-flow scenarios and five aircraft were added to original west-flow scenarios to provide a slightly higher traffic load (denoted E1+ through E4+ and W1+ through W4+). In concert with changes to the TMA-TM and the west-flow route adaptation between the 5.2 and 5.3 simulations, the west-flow scenarios were also modified slightly by moving a few turboprops and pistons to the beginning of the scenarios to avoid interactions with FIM aircraft (denoted W1++ through W4++). In isolated cases, single aircraft were added or deleted due to conflicts at initialization, flight-plan related issues, or other factors (see Table 1).

\section{Participants and Training}

Experimental subjects were recently retired PHX and ZAB controllers. Four terminal-area controllers staffed two Feeder and two Final positions. Center controllers staffed the four low-altitude center sectors, as well as four highaltitude sectors. To the extent possible, subject controllers were assigned to the sectors most in keeping with their professional experience. Two controllers with suitable experience also served as ZAB TMC and P50 TMC/ARC. Other controllers with AOL experience served as confederates, staffing two center sectors designed to surround the study airspace, as well as the tower and a departure sector. Eight glass-cockpit pilots flew the ASTOR single-pilot desktop simulators; in addition, eighteen regional jet pilots and aviation students staffed pseudo-pilot positions. The laboratory layout was the same for all three simulations (Fig. 12).

Because the participants had, on average, 30 years experience in current-day PHX operations, the 5.1 simulation was preceded by three days of training during which participants received instruction primarily on MACS specifics, working with pseudo-pilots, the AOL voice communications system, and reviewing the applicable Letters of Agreement (LOAs). The 5.2 simulation began with four days of training to give participants more time to gain familiarity with ATD-1 operations and to practice metering and using the CMS tools. 5.3 similarly began with four days of training that included in-depth reviews of metering and CMS operations, and detailed instruction on FIM operations. FIM operations aside, basic guidelines for 5.2 and 5.3 were to absorb the appropriate amount of delay, deliver aircraft to the meter fixes within +/- $30 \quad \mathrm{~s}$ of their

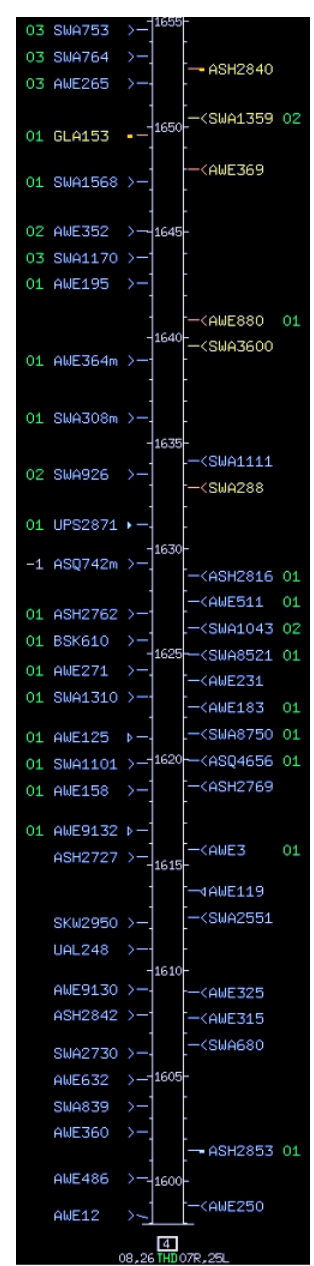

(a)

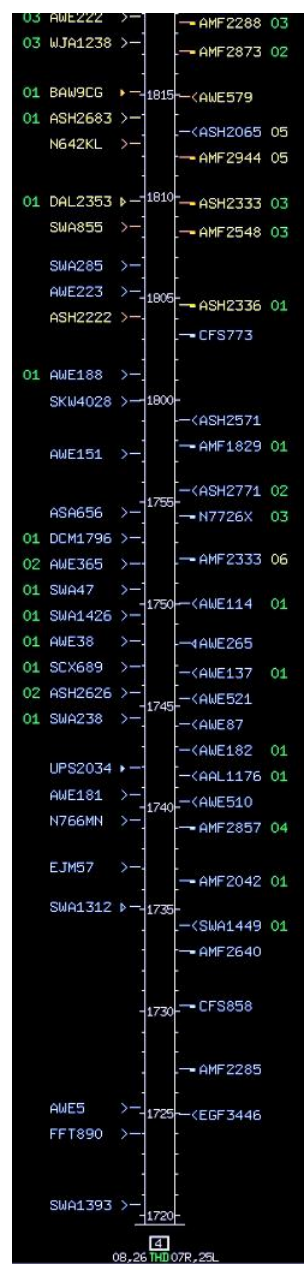

(b)
Figure 11. Example schedules for east- (a) and west-flow (b) traffic.

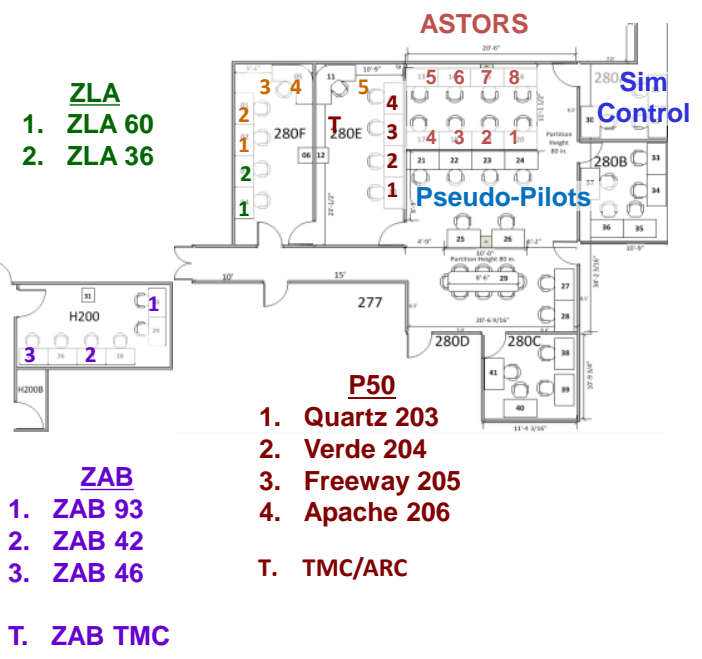

Figure 12. AOL layout for the 5.1, 5.2, and 5.3 simulations. 
scheduled times (with preference for delivering aircraft slightly early), keep the aircraft in the slot markers for delivery to the Final, and ensure proper wake-vortex spacing on final approach.

The majority of the subject controllers were the same across the three simulations. The exceptions were the ZAB TMC, who was replaced with a more recently retired ZAB TMC for the 5.3 simulation; the north-side Final (Freeway) controllers (due to availability issues, a different individual served in that capacity in each simulation); and the north-side Feeder (Apache), who was replaced for 5.3 due to illness.

\section{E. Data Collection}

Four days of data collection took place during each simulation. In 5.1 and 5.2 data were collected for each of the sixteen traffic scenarios in randomized order. Due to changes that occurred between 5.2 and 5.3, the fourth (most benign) wind condition was dropped, and data were collected for the E1+, E2+, E3+, W1++, W2++, and W3++ scenarios three times each - once without FIM and twice with FIM-eligible ASTORs. The 5.3 trials without FIM were conducted to collect data for operations with the changes to the ATD-1 ground tools that could be directly compared to the 5.3 trials with FIM.

All MACS stations and desktop flight simulators logged digital data (as did the data-communication hubs), including flight state information, pilot and controller entries, and schedule information. The TMA-TM and the ASTOR simulators also logged digital data. All participants completed short questionnaires between trials, and a longer questionnaire at the end of the week. In addition, screen-capture movies that include recorded audio were collected from all MACS and ASTOR stations, and AOL laboratory staff and a variety of subject-matter experts served as observers. Subjects were encouraged to alert observers to any events not typical of their experience piloting or working live traffic. Each simulation also closed with group de-brief discussion. Nearly 3 TB of digital data alone were collected during the three simulations.

\section{Results}

This section describes results relevant to efficiency under high-throughput operations using the ATD-1 groundbased technologies. It begins with general observations about characteristics of the operations in each of the 5.1, 5.2, and 5.3 simulations that may be important to consider when interpreting particular metrics.

\section{A. General Observations}

At the highest level, managing traffic using the TMA-TM and CMS tools constitutes a fundamental shift in operations from current-day PHX traffic management methods. Managing traffic to a global plan, in the form of an arrival schedule with specified routings and runway assignments, improves predictability but also introduces interdependencies in the system that are not present in today's operations. If successive controllers each absorb the appropriate amount of delay for each aircraft, so that aircraft reach the Final controllers in their slot markers, the system works smoothly as intended. If, on the other hand - due to a lack of proficiency with the tools, unintended aircraft behavior, communication problems, or any other distraction - controllers are unable to manage each aircraft without difficulties, downstream controllers may have to revert to current-day techniques to ensure separation, disrupting operations until a schedule-gap is available in which to recover.

In the baseline 5.1 simulation, subject controllers demonstrated the impressive skills to be expected from 30 years of experience. High-altitude center controllers sequenced the flows and provided appropriate miles-in-trail spacing to the low-altitude controllers, enabling low-altitude controllers to descend aircraft 'via' the RNAV arrivals. The TRACON TMC/ARC coordinated with TRACON controllers to insert non-RNAV arrivals into the flows. The TRACON Feeder controllers aggressively directed traffic to the Finals, who ran short Finals with very tight spacing. Because the vast majority of their experience was under Visual operations, however, the Finals did not show great concern for $2.5 \mathrm{nmi}$ spacing minimums - particularly when they were busy.

In the 5.2 and 5.3 simulations, controllers new to metering and the control techniques required for the ATD-1 operations exhibited varying levels of proficiency, frustration, and acceptance. Any 'bumps' in the operation could be magnified, and some controllers did not always place a premium on schedule-recovery. The TRACON TMC/ARC at times sought to help by adjusting the schedule. Again spacing violations were noted on final approach. Despite individual differences, controllers persevered, attempted to coordinate with each other to find mutually acceptable aircraft states at handoff, and largely provided thoughtful feedback on the operations. On the whole, controllers adapted to the ATD-1 operations well, and relished the opportunity to participate in the simulations.

Together with the added experience imparted during 5.2, the TMA-TM improvements generally resulted in smoother ground-tool operations during the 5.3 simulation. The ERAM DCTs were more stable, which made metering somewhat easier. Once established in their slot markers, aircraft tended to stay on schedule. Scheduling all 
arrivals in 5.3 generally reduced uncertainty and the schedule was nearly always accepted without substantive modifications by the P50 TMC/ARC.

\section{B. Arrival Operations by Simulation Trial}

Table 1 provides an overview of the arrival operations during each simulation trial. The type of operations are specified as current-day ('Current'), operations with ATD-1 ground-based technologies only ('GT'), and operations including FIM ('GT + FIM'). Scenarios are designated according to the scheme described in Section III.C. Two 5.3 scenarios were cut short by simulation infrastructure problems, as shown in the Duration column.

The numbers of aircraft that landed on the north and south runways are augmented with information about how many of those aircraft were crossovers. In the 5.1 simulation, relatively few crossovers resulted from TMC/ARC

Table 1. Summary of arrival operations.

\begin{tabular}{|c|c|c|c|c|c|c|c|}
\hline Simulation & Operations & Scenario & Duration (min) & Arrivals & Landed & $\begin{array}{c}\text { North Runway } \\
\text { (Crossovers) }\end{array}$ & $\begin{array}{c}\text { South Runway } \\
\text { (Crossovers) }\end{array}$ \\
\hline "5.1 & Current & E1 & 58 & 118 & 42 & 18 & 24 \\
\hline 5.1 & Current & E1+ & 60 & 124 & 46 & $20(1)$ & $26(1)$ \\
\hline 5.1 & Current & E2 & 60 & 118 & 44 & 20 & 24 \\
\hline 5.1 & Current & E2+ & 60 & 124 & 47 & $21(1)$ & $26(1)$ \\
\hline 5.1 & Current & E3 & 60 & 118 & 49 & $25(1)$ & $24(1)$ \\
\hline 5.1 & Current & E3+ & 57 & 124 & 41 & 19 & 22 \\
\hline 5.1 & Current & E4 & 61 & 118 & 44 & 20 & 24 \\
\hline 5.1 & Current & E4+ & 60 & 124 & 47 & 20 & 27 \\
\hline 5.1 & Current & W1 & 58 & 144 & 41 & 21 & $20(1)$ \\
\hline 5.1 & Current & W1+ & 61 & 149 & 47 & 23 & $24(1)$ \\
\hline 5.1 & Current & W2 & 57 & 144 & 42 & 22 & $20(3)$ \\
\hline 5.1 & Current & $\mathrm{W} 2+$ & 60 & 149 & 48 & $25(1)$ & $23(1)$ \\
\hline 5.1 & Current & W3 & 59 & 144 & 43 & 22 & $21(2)$ \\
\hline 5.1 & Current & W3+ & 58 & 149 & 44 & 23 & $21(1)$ \\
\hline 5.1 & Current & W4 & 59 & 144 & 40 & 20 & $20(3)$ \\
\hline 5.1 & Current & W4+ & 58 & 149 & 48 & 25 & $23(3)$ \\
\hline 5.2 & GT & E1 & 55 & 118 & 40 & $19(2)$ & 21 \\
\hline 5.2 & GT & E1+ & 60 & 124 & 45 & $21(2)$ & 24 \\
\hline 5.2 & GT & E2 & 59 & 118 & 43 & 19 & 24 \\
\hline 5.2 & GT & E2+ & 60 & 124 & 48 & 22 & 26 \\
\hline 5.2 & GT & E3 & 60 & 118 & 46 & 22 & 24 \\
\hline 5.2 & GT & E3+ & 60 & 124 & 49 & $24(1)$ & 25 \\
\hline 5.2 & GT & E4 & 56 & 118 & 41 & $20(1)$ & 21 \\
\hline 5.2 & GT & E4+ & 58 & 124 & 45 & $21(1)$ & 24 \\
\hline 5.2 & GT & W1 & 60 & 145 & 43 & 22 & 21 \\
\hline 5.2 & GT & W1+ & 60 & 149 & 44 & 23 & 21 \\
\hline 5.2 & GT & W2 & 61 & 145 & 45 & $25(2)$ & $20(1)$ \\
\hline 5.2 & GT & $\mathrm{W} 2+$ & 60 & 149 & 46 & 25 & $21(1)$ \\
\hline 5.2 & GT & W3 & 60 & 145 & 43 & $23(1)$ & 20 \\
\hline 5.2 & GT & W3+ & 55 & 149 & 39 & $21(1)$ & $18(1)$ \\
\hline 5.2 & GT & W4 & 56 & 144 & 38 & $20(1)$ & $18(3)$ \\
\hline 5.2 & GT & W4+ & 60 & 150 & 46 & 26 & 20 \\
\hline 5.3 & GT & E1+ & 60 & 124 & 45 & $21(2)$ & 24 \\
\hline 5.3 & GT + FIM & E1+ & 60 & 124 & 45 & $24(4)$ & 21 \\
\hline 5.3 & GT + FIM & E1+ & 60 & 124 & 45 & $22(3)$ & 23 \\
\hline 5.3 & GT & E2+ & 60 & 124 & 47 & $23(2)$ & 24 \\
\hline 5.3 & GT + FIM & E2+ & 60 & 124 & 47 & $23(2)$ & 24 \\
\hline 5.3 & $\mathrm{GT}+\mathrm{FIM}$ & E2+ & 47 & 124 & 34 & $17(2)$ & 17 \\
\hline 5.3 & GT & E3+ & 60 & 124 & 49 & $24(1)$ & 25 \\
\hline 5.3 & $\mathrm{GT}+\mathrm{FIM}$ & E3+ & 60 & 124 & 49 & $24(1)$ & 25 \\
\hline 5.3 & $\mathrm{GT}+\mathrm{FIM}$ & E3+ & 60 & 124 & 49 & $24(1)$ & 25 \\
\hline 5.3 & GT & W1++ & 60 & 140 & 42 & $21(2)$ & $21(3)$ \\
\hline 5.3 & GT + FIM & $\mathrm{W} 1++$ & 60 & 140 & 41 & 20 & $21(3)$ \\
\hline 5.3 & GT + FIM & W1++ & 60 & 140 & 42 & $22(3)$ & $20(3)$ \\
\hline 5.3 & GT & $\mathrm{W} 2++$ & 60 & 140 & 42 & $21(2)$ & $21(5)$ \\
\hline 5.3 & $\mathrm{GT}+\mathrm{FIM}$ & $\mathrm{W} 2++$ & 60 & 140 & 43 & $23(3)$ & $20(5)$ \\
\hline 5.3 & $\mathrm{GT}+\mathrm{FIM}$ & $\mathrm{W} 2++$ & 65 & 140 & 44 & $23(2)$ & $21(4)$ \\
\hline 5.3 & GT & W3++ & 60 & 140 & 38 & 19 & $19(4)$ \\
\hline 5.3 & GT + FIM & W3++ & 46 & 140 & 25 & $12(1)$ & $13(3)$ \\
\hline 5.3 & GT + FIM & W3++ & 60 & 140 & 41 & $20(1)$ & $21(5)$ \\
\hline
\end{tabular}

11

American Institute of Aeronautics and Astronautics 
decisions and coordination with the TRACON controllers. In 5.2, crossovers resulted from TMA-TM scheduling in addition to TMC/ARC involvement. In 5.3, with TMATM runway-allocation in use, greater numbers of crossovers were scheduled to balance runway utilization. The 5.3 west-flow scenarios had a particularly large number of crossovers, because scheduling small aircraft using the adapted routes to runway $25 \mathrm{~L}$ (see Fig. 5 ) at times resulted in crossovers to runway 26 for runway balancing. TRACON controllers sometimes felt these 'dualcrossover' situations introduced needless complexity.

\section{Example Plots}

Figures 13 and 14 depict plan- and profile-view plots of landing aircraft for comparable scenarios in each simulation. Figure 13 shows plots from E1+ trials. For the more structured flows in this east-flow scenario, the subject controllers were able to manage the flows with a high degree of efficiency using current-day control techniques in the 5.1 simulation. They extended the downwinds for only a few aircraft and enabled continuous descents with shorter ground tracks for many. In 5.2, the controllers achieved better conformance with the RNAV



Figure 13. E1+ scenario plots from 5.1 (top), 5.2 (middle), and 5.3 (bottom).

lateral routes, but experienced some difficulties with a few aircraft that led to trouble maintaining the schedule. In 5.3 controllers avoided such problems, yielding near-perfect conformance with the TMA-TM adapted routes together with excellent descent efficiency.

Plots from the more complex W2+ scenario (for 5.3, W2++ without FIM) are shown in Fig. 14. The 5.1 plots illustrate the extra work required to integrate the turboprops and pistons, with considerable vectoring and extended downwinds to absorb delay at low altitudes. In 5.2 the controllers adopted the strategy of penalizing unscheduled arrivals, vectoring them until they could be easily fit into gaps in the schedule. The result is that most RNAV arrivals exhibit high conformance with the adapted routes. In addition, very consistent long- and short-side descent profiles are visible. The plots from the 5.3 west-flow scenario clearly depicts the heavy use of crossover routes, and the resulting vectoring paths. The crossovers require extra coordination in the TRACON, and increased workload is exacerabated by the difficulty of heavy vectoring using pseudo-pilots responsible for multiple aircraft. Despite these problems, a large number of efficient descents are again evident, as well as mostly normal final-approach intercepts. 


\section{PBN Success Rate}

PBN success is an ATD-1 Measure of Performance that simply measures whether eligible aircraft are allowed to remain on RNAV arrivals without being vectored until they normally would be (i.e., to turn base, or begin crossing over to the other runway). Figure 15 shows the improvement of the PBN-success-rate measure from 5.1 to 5.2 ; further improvement in 5.3 is shown in Fig. 16 (' $F$ ' designates a 'GT + FIM' trial). The 5.3 measures exceed the desired margin for improvement specified for ATD-1. However, this metric should be viewed with caution, as it does not capture whether aircraft that remained on the RNAV lateral routings performed efficient descents with high throughput or not.

\section{E. Flight Time and Distance}

Measures of flight time and distance are often used as surrogate fuel-efficiency measures. The average times and distances aircraft took to transit the low-altitude center sectors and the TRACON were computed for landing aircraft along the primary EAGUL, MAIER, and GEELA flows for the 5.1, 5.2, and 5.3 simulations (only for trials without FIM). To focus the analysis on highthroughput operations, the number of aircraft that landed on the same runway within five minutes before and after a given
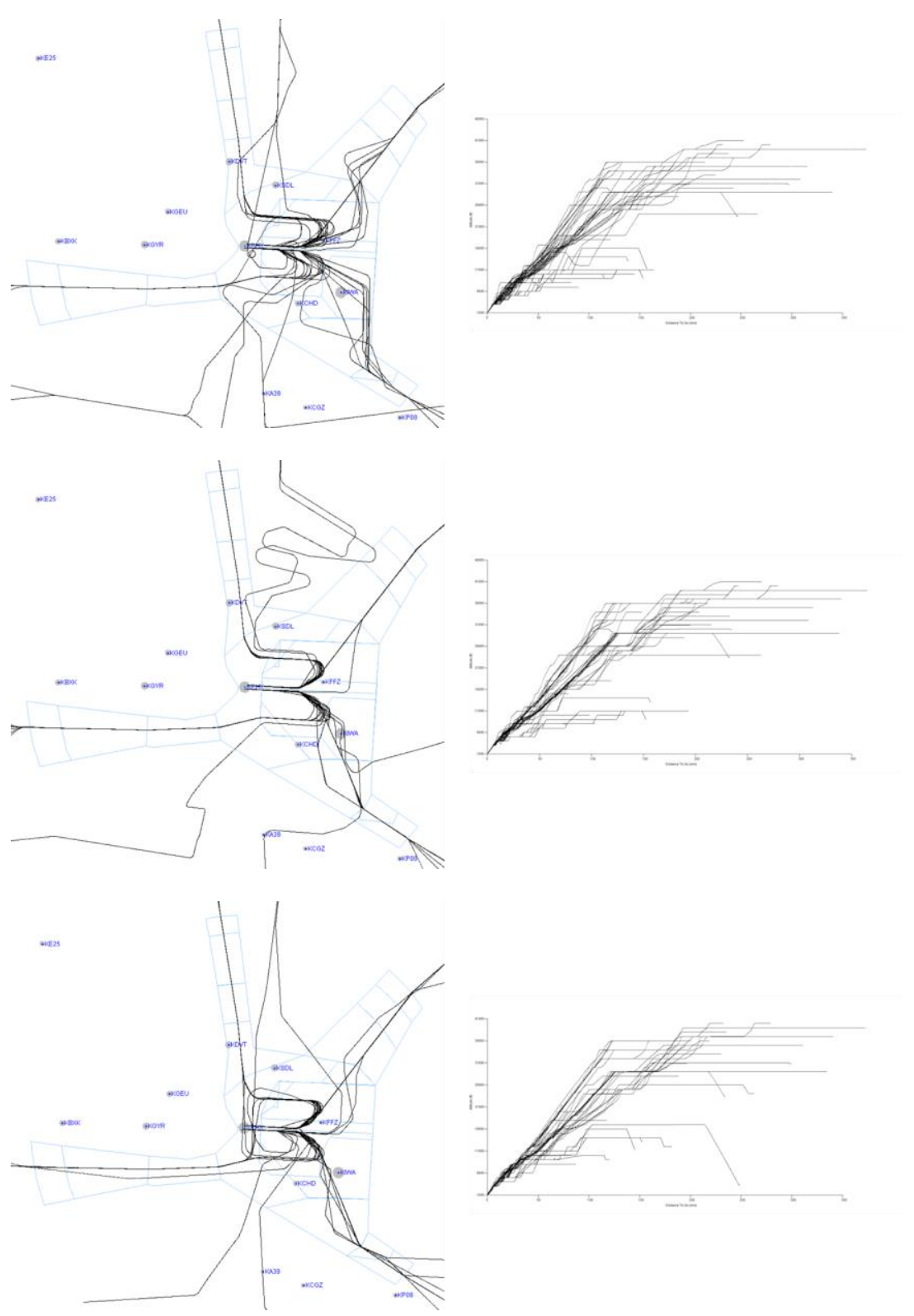

Figure 14. W2+ scenario plots from 5.1 (top) and 5.2 (middle), and the W2++ scenario from 5.3 (bottom).



Figure 15. PBN success rate for 5.1 and 5.2.



Figure 16. PBN success rate for 5.3.

American Institute of Aeronautics and Astronautics 
aircraft were counted, and only aircraft for which the throughput indicator was greater than or equal to 30 aircraft/hr were considered. For many flows, these metrics show few discernable differences, perhaps because aircraft remained on or near their assigned RNAV arrivals or because controllers largely applied similar strategies to manage aircraft in their sector, whether or not the ATD-1 ground-based technologies were in use.

Figures 17 and 18 show the average flight times and distances in low-altitude sectors for east-flow non-FIM trials. By these measures, aircraft on the EAGUL arrival to runway 08, aircraft tended to exhibit greater efficiency on average under current-day operations in the 5.1 simulation, while the GEELA_PHX08 saw a slight flight time reduction with ground tools. The east-flow TRACON times and distances suggest aircraft on some flows were managed with slower speeds in 5.2 and 5.3 (Fig. 19 and Fig. 20). However, variation in flight distance was significantly reduced in 5.2 and 5.3, suggesting more consistent PBN operations.

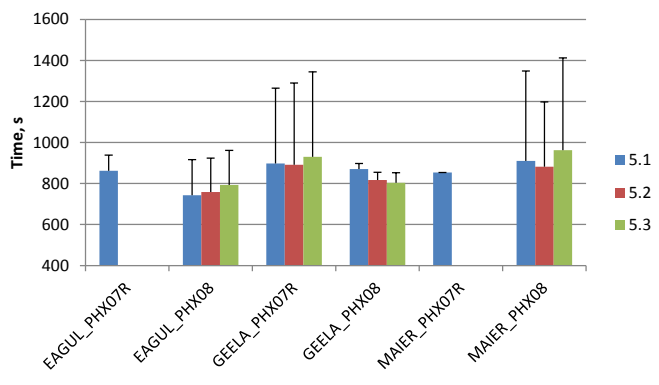

Figure 17. Average low-altitude center sector flight times for east-flow scenarios.



Figure 19. Average TRACON flight times for east-flow scenarios.

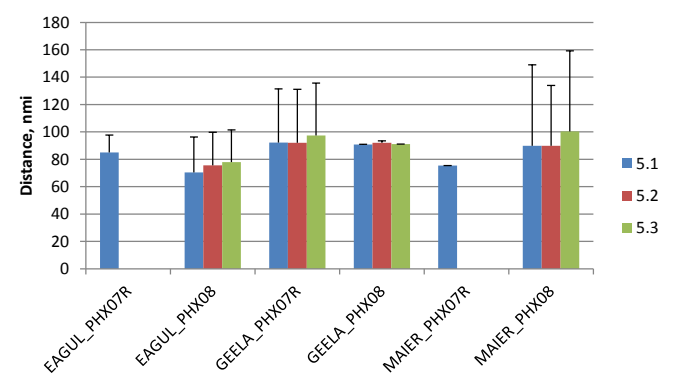

Figure 18. Average low-altitude center sector flight distances for east-flow scenarios.

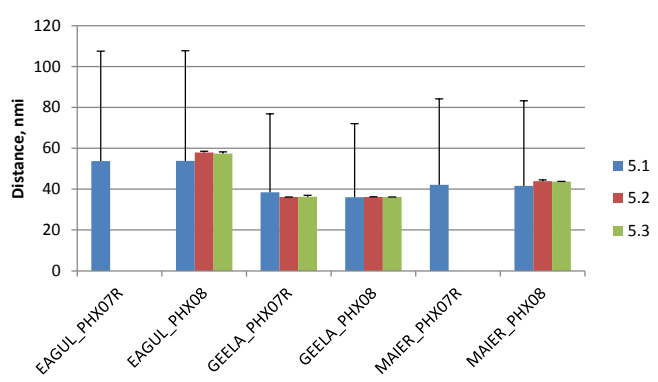

Figure 20. Average TRACON flight distances for east-flow scenarios.

Low-altitude-sector results for west-flow non-FIM trials are shown in Figs. 21 and 22. EAGUL flight times varied less, and the GEELA flow was managed slightly more efficiently, in the 5.3 simulation. TRACON times and distances shown in Figs. 23 and 24 suggest indicate aircraft experienced slight but consistent distance reductions on the EAGUL and GEELA flows.

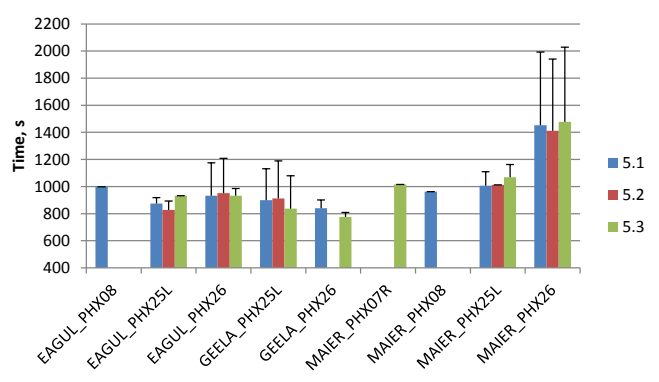

Figure 21. Average low-altitude center sector flight times for west-flow scenarios.

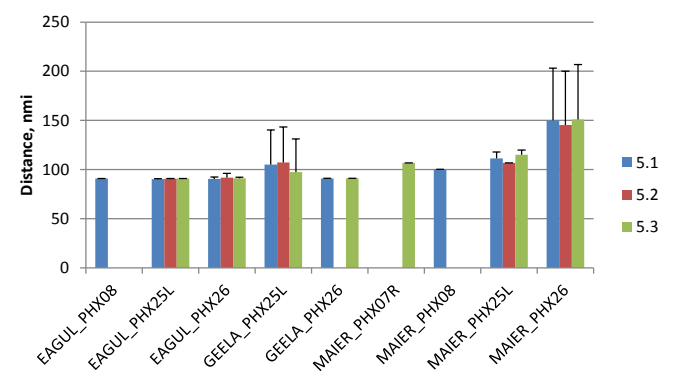

Figure 22. Average low-altitude center sector flight distances for east-flow scenarios. 


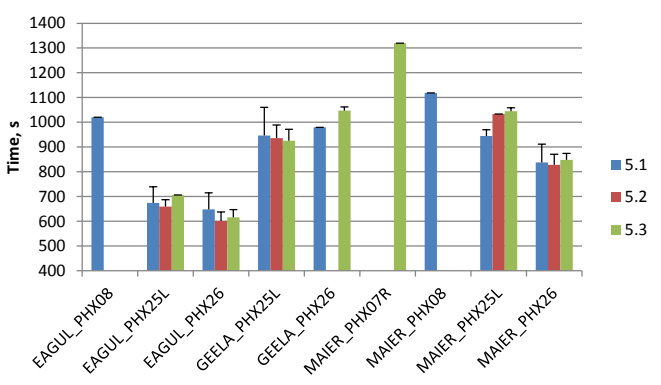

Figure 23. Average TRACON flight times for west-flow scenarios.

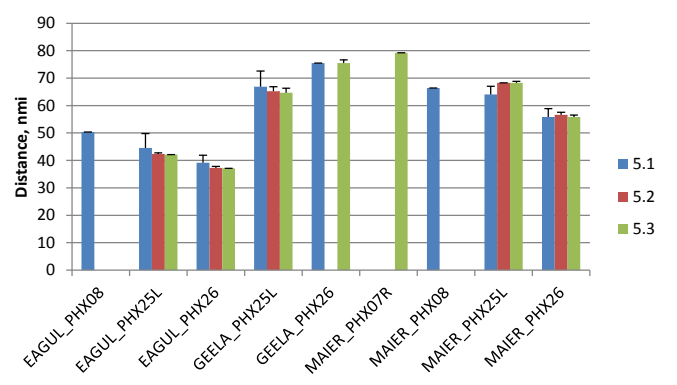

Figure 24. Average TRACON flight distances for east-flow scenarios.

\section{F. Manageability and Tool Use}

Questionnaire results include responses from all simulation trials. Figures 25-27 show the mean ratings of the overall manageability of traffic during the three simulations. Controllers who staffed the high-altitude sectors rated traffic as 'manageable' in the 5.1 and 5.3 simulations, and only 'fairly manageable' in 5.2. Low-altitude controllers gave similar ratings, and reported a slight increase in west-flow manageability from 5.2 to 5.3. In the TRACON, traffic was rated 'manageable,' with the highest ratings in the 5.2 simulation.

Related questions addressed the achievability of the schedule and how well the flows were conditioned in the 5.2 and 5.3 simulations when the TMA-TM provided schedule information. Figure 28 shows that schedule-achievability ratings improved from 5.2 to 5.3. The TRACON controllers rated the schedule as 'achievable' on average, while the center controllers found it 'fairly achievable.'

Tool-usage questions also reflected improvements in the TMA-TM schedule in the 5.3 simulation. High-altitude controllers registered slight increases in their reported use of the meter list and DCTs, and abandoned use of the scratchpad (Fig. 29). Low-altitude controllers also reported using the DCTs more, in addition to the runway indicator and the meter-list during west-flow scenarios (Fig. 30). In the TRACON, slot markers were again used the most, followed by the sequence numbers and speed advisories (Fig. 31). Interestingly, TRACON controllers never reported using the TMA-TM-estimated aircraft airspeed.

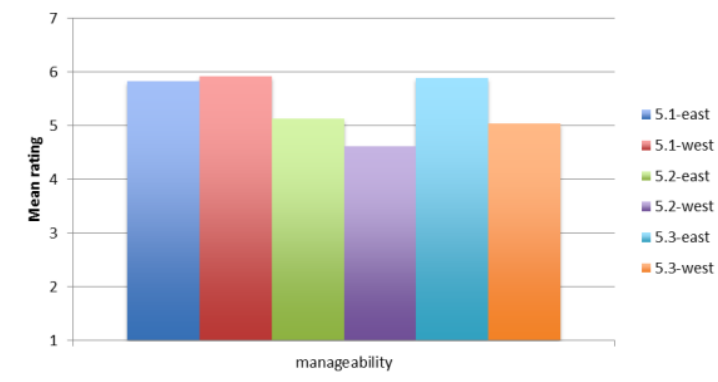

Figure 25. Average center high-altitude manageability ratings.

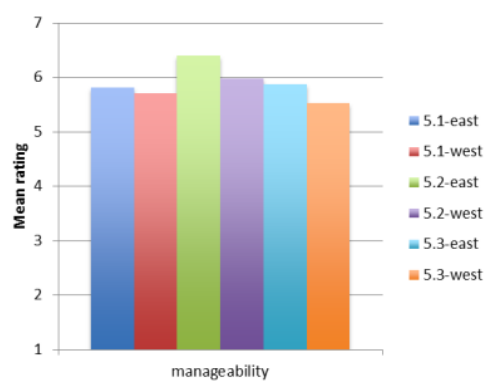

Figure 27. Average TRACON manageability ratings.

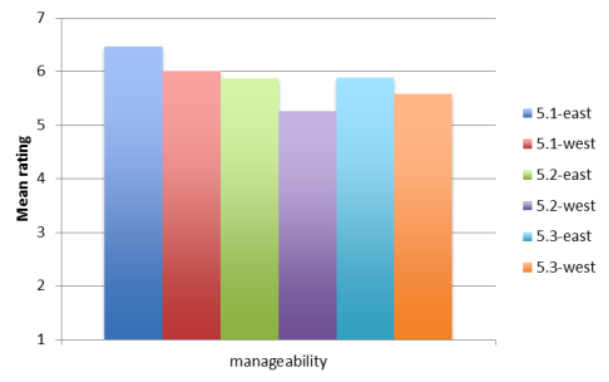

Figure 26. Average center low-altitude manageability ratings.

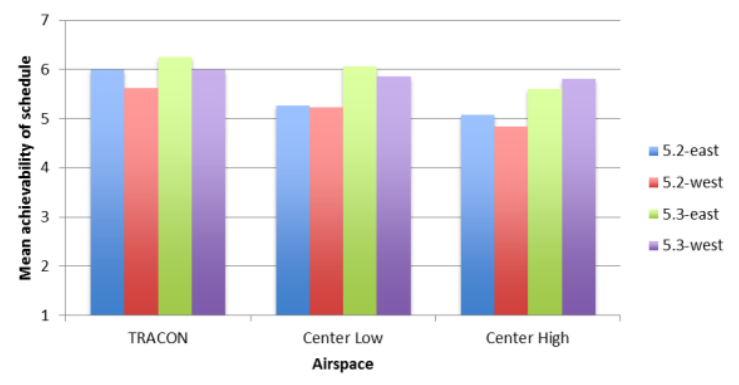

Figure 28. Schedule achievability ratings. 


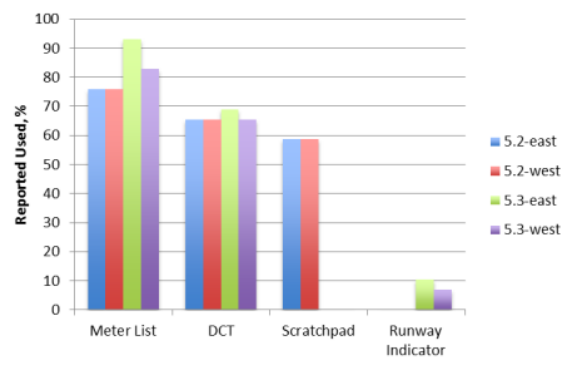

Figure 29. Center high-altitude controller tool usage.

\section{G. Workload}

Workload data were collected both in real-time, using Workload Assessment Keypad (WAK) functionality integrated in the MACS controllers workstations, and via questionnaires. As shown in Fig. 32 , the average value of WAK ratings collected every three minutes during all simulation trials stayed below a rating of 3 on a scale of 1 to 6 . Only the 5.1 and 5.3 ratings were found to be significantly different.

NASA TLX ratings from the questionnaire data show that on average workload ranged from 'reasonably low' to 'moderate' during the simulations. High-altitude controllers found the 5.3 east-flow scenarios most demanding (Fig. 33). (Note that 'success' ratings are plotted as the inverse of the rating.) Low-altitude controllers also found the 5.3 east-flow scenarios challenging-a reversal from 5.2, when the west-flow scenarios received higher ratings (Fig. 34). The TRACON controllers continued to rate west-flow workload as 'moderate' in 5.3, but east-flow workload dropped to 5.1 ratings-levels on most TLX subscales (Fig. 35).



Figure 32. Average WAK ratings across all controllers for the 5.1, 5.2, and 5.3 simulations.
Figure 30. Center low-altitude controller tool usage.

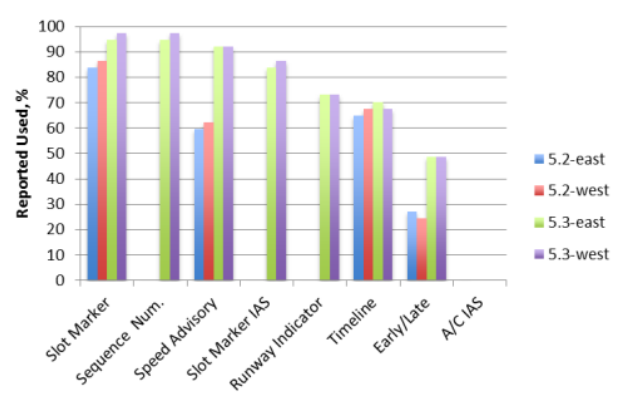

Figure 31. TRACON controller tool usage. 


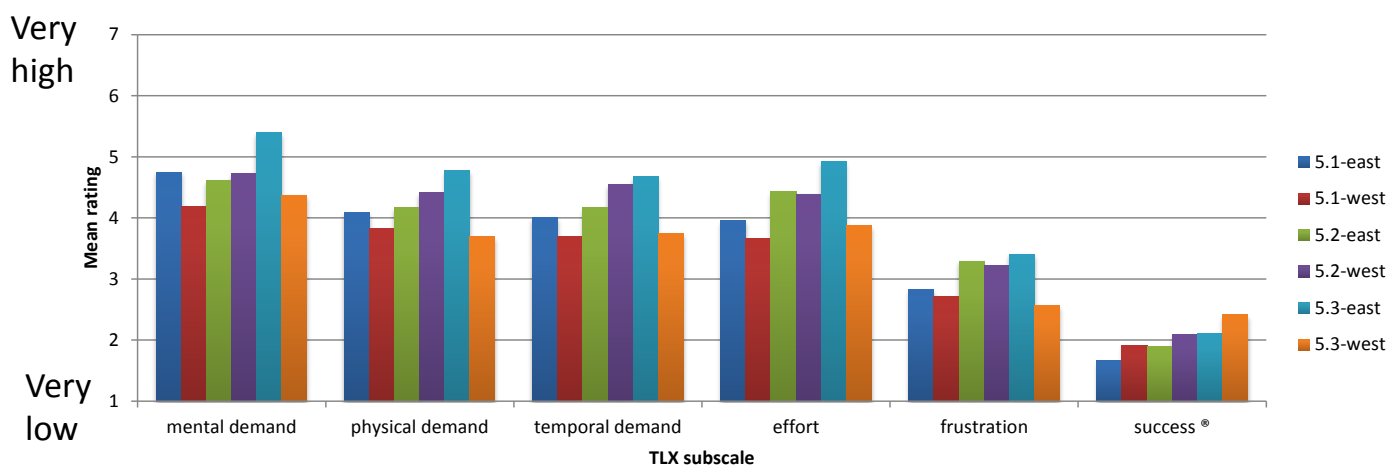

Figure 33. Average center high-altitude controller TLX ratings.

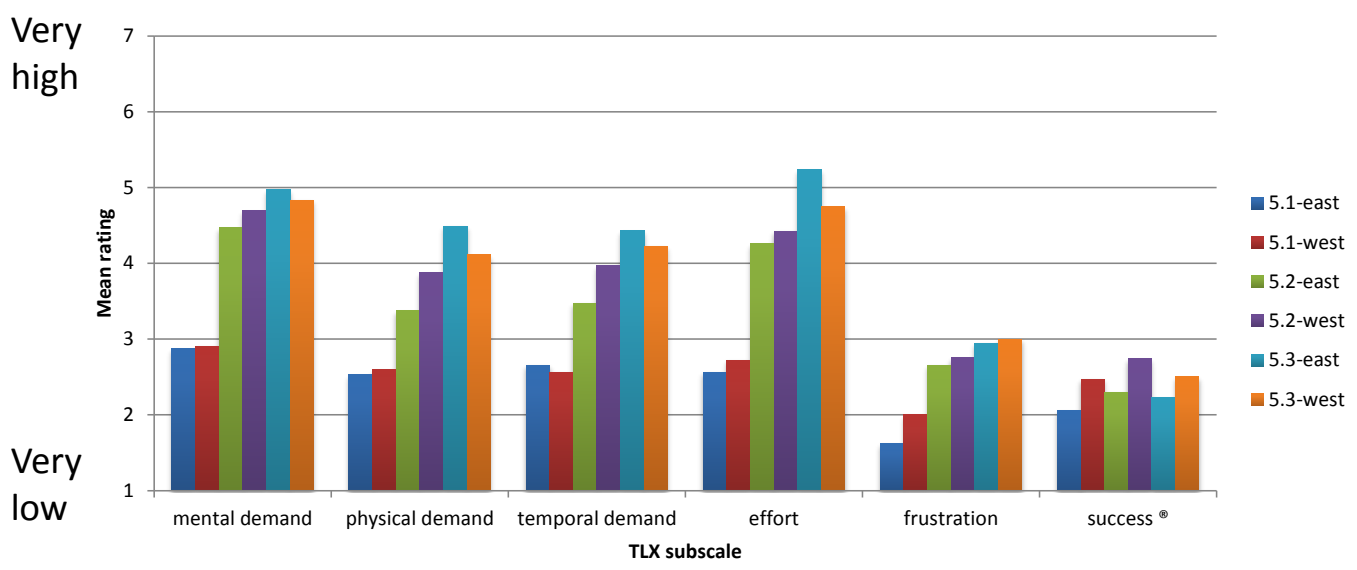

Figure 34. Average center low-altitude controller TLX ratings.



Figure 35. Average TRACON controller TLX ratings.

\section{Conclusion}

The results indicate that, at a system-level, the ATD-1 ground-based technologies support increased PBN operations for high-density traffic. Positive effects of the tools most evident in the west-flow scenarios, when the arrival traffic was least homogenous; the schedule provided a workable plan that controllers would otherwise have to formulate on the fly. Improvements to the TMA-TM to provide accurate airspeed predictions for the 5.3 simulation resulted in improved schedule-achievability along with increased DCT and speed-advisory usage. 
Scheduling all aircraft enabled smoother operations overall, but sometimes led to unnecessary crossovers in 5.3. Inter-arrival spacing data still require detailed comparisons across the studies. Those results were not presented due to their close relationship with FIM operations. Problems maintaining inter-arrival spacing in the absence of FIM may in part be due to the subject controllers' extensive experience operating in Visual conditions in PHX, but mitigation measures such as increasing the TMA-TM scheduling buffer nonetheless deserve consideration. Issues related to aircraft amd FMS behavior under ATD-1 operations also warrant further investigation. ${ }^{17}$

Overall the results suggest controllers can adapt their techniques to utilize the tools without an undue increase in workload and coordinate their actions via a global schedule to manage arrival traffic in a more integrated and predictable fashion than is possible today. The 5.2 and 5.3 simulations frame expectations for introductory operations - the system-level performance and controller responses that could be expected when controllers are first experiencing the TMA-TM and CMS tools. That center controllers new to metering and TRACON controllers used to vectoring traffic for sequencing perform as observed in a highly complex simulation environment-after only a few days of training - reflects positively on the tools and on the efforts of the ATD-1 integration and development team. Further performance increments can be expected as controllers gain experience and the technologies are refined through use.

Technology-transfer of the the ATD-1 ground-based technologies to the FAA in support of Time-Based Flow Management (TBFM) and TSS is underway. Prototype Standard Terminal Area Replacement System (STARS) controller workstations that implement CMS tools have also been developed and validated in the ATC Laboratory at NASA Ames. These activities also serve an important gauge of ATD-1 success to date.

\section{Acknowledgments}

This research was conducted as part of NASA's Air Traffic Management Technology Demonstration-1, John Robinson III, Technical Lead. The authors wish to thank the many ATD-1 researchers, pilot trainers, and support personnel at NASA Ames and NASA Langley who helped with this research.

\section{References}

${ }^{1}$ Prevot, T., Baxley, B., Callantine, T., Johnson, W., Quon, L., Robinson, J., and Swenson, H., "NASA's ATM Technology Demonstration-1: Transitioning Fuel Efficient, High Throughput Arrival Operations from Simulation to Reality," Proceedings of the International Conference on Human-Computer Interaction in Aerospace (HCI-Aero 2012), Brussels, September 2012.

${ }^{2}$ Murdoch, J., Barmore, B., Baxley, B., Abbott, T., and Capron, W., "Evaluation of an Airborne Spacing Concept to Support Continuous Descent Arrival Operations," Proceedings of the $8^{\text {th }}$ USA/Europe Air Traffic Management Research and Development Seminar (ATM2009), Napa, CA, June 2009.

${ }^{3}$ Swieringa, K., Murdoch, J., Baxley, B., and Hubbs, C., "Evaluation of an Airborne Spacing Concept, On-board Spacing Tool, and Pilot Interface," Proceedings of the $11^{\text {th }}$ Aviation Technology Integration and Operations (ATIO) Conference, Virginia Beach, VA, September 2011.

${ }^{4}$ Shay, R., Swieringa, K., and Baxley, B., "Aircraft Configuration and Flight Crew Compliance with Procedures While Conducting Flight deck based Interval Management (FIM) Operations," Proceedings of the $12^{\text {th }}$ Aviation Technology Integration and Operations (ATIO) Conference, Indianapolis, September 2012.

${ }^{5}$ Callantine, T., Cabrall, C., Kupfer, K., Martin, L., Mercer, J., and Prevot, T., "Initial Investigations of Controller Tools and Procedures for Schedule-Based Arrival Operations with Mixed Flight-Deck Interval Management Equipage," Proceedings of the $12^{\text {th }}$ Aviation Technology Integration and Operations (ATIO) Conference, Indianapolis, September 2012.

${ }^{6}$ Callantine, T., Kupfer, K., Martin, L., and Prevot, T., "Simulations of Continuous Descent Operations with ArrivalManagement Automation and Mixed Flight-Deck Interval Management Equipage," Proceedings of the 10 ${ }^{\text {th }}$ USA/Europe Air Traffic Management Research and Development Seminar (ATM2013), Chicago, June 2013.

${ }^{7}$ Swenson, H., Thipphavong, J., Sadovsky, A., Chen, L., Sullivan, C., and Martin, L., "Design and Evaluation of the Terminal Area Precision Scheduling and Spacing System," Proceedings of the $9^{\text {th }}$ USA/Europe Air Traffic Management Research and Development Seminar (ATM2011), Berlin, June 2011.

${ }^{8}$ Thipphavong, J., Swenson, H., Lin, P., Seo, A, and Bagasol, L., "Efficiency Benefits Using the Terminal Area Precision Scheduling and Spacing System," Proceedings of the $11^{\text {th }}$ Aviation Technology Integration and Operations (ATIO) Conference, Virginia Beach, VA, September 2011.

${ }_{9}^{9}$ Jung, J., Swenson, H., Thipphavong, J., Martin, L., Chen, L., and Nguyen, J., "Evaluation of the Terminal Area Precision Scheduling and Spacing System for Performance-Based Navigation Arrivals," Proceedings of the $32^{\text {nd }}$ Digital Avionics Systems Conference, Syracuse, NY, October 2013.

${ }^{10}$ Thipphavong, J., Jung, J., Swenson, H., Martin, L., Lin, M., and Nguyen, J., "Evaluation of the Terminal Sequencing and Spacing System for Performance-Based Navigation Arrivals," Proceedings of the $32^{\text {nd }}$ Digital Avionics Systems Conference, Syracuse, NY, October 2013. 
${ }^{11}$ Kupfer, M., Callantine, T., Martin, L., Mercer, J., and Palmer, E., "Controller Support Tools for Schedule-Based Terminal Operations," Proceedings of the $9^{\text {th }}$ USA/Europe Air Traffic Management Research and Development Seminar (ATM2011), Berlin, June 2011.

${ }^{12}$ Prevot, T., How to Compute a Slot Marker - Calculation of Controller-Managed Spacing Tools for Efficient Descents with Precision Scheduling, ," Proceedings of the 31 $1^{\text {st }}$ Digital Avionics Systems Conference, Williamsburg, VA, October 2012.

${ }^{13}$ Baxley, B., Swenson, H., Prevot, T., and Callantine, T., "NASA's ATM Technology Demonstration-1: Integrated Concept of Arrival Operations," Proceedings of the 31 ${ }^{\text {st }}$ Digital Avionics Systems Conference, Williamsburg, VA, October 2012.

${ }^{14}$ Baxley, B., Johnson, W., Swenson, H., Robinson, J., Prevot, T., Callantine, T., Scardina, J., and Greene, M., Air Traffic Management Technology Demonstration-1 concept of operations (ATD-1 ConOps v2.0). NASA Technical Memorandum 2013218040. Hampton, VA: NASA Langley Research Center, September 2013.

${ }^{15}$ Sprong, K., and Mayer, R., "Analysis of RNAV Arrival Operations with Descend Via Clearances at Phoenix Airport," Proceedings of the $26^{\text {th }}$ Digital Avionics Systems Conference, Dallas, October 2007.

${ }^{16}$ Callantine, T., Palmer, E., and Kupfer, M., "Human-in-the-Loop Simulation of Trajectory-Based Terminal-Area Operations," Proceedings of the 27th International Congress of the Aeronautical Sciences (ICAS2010), Nice, France, September 2010 .

${ }^{17}$ Kaneshige, J., Sharma, S., Martin, L., Lozito, S., Dulchinos, V., "Flight-Deck Strategies and Outcomes When Flying Schedule-Matching Descents," Proceedings of the 2013 Guidance, Navigation, and Control (GNC) Conference, Boston, August 2013. 